\title{
Government's Involvement in Safety Management in Public Early Childhood Education Centres (ECECs) in Rivers State, Nigeria
}

\author{
Igbinedion, Doye Angela ${ }^{1}$, Abraham, N. M. ${ }^{1, *} \&$ Nwogu, U. J. ${ }^{1}$ \\ ${ }^{1}$ Department of Educational Management, Faculty of Education, University of Port Harcourt, Port Harcourt, Nigeria \\ *Correspondence: Department of Educational Management, Faculty of Education, University of Port Harcourt, Port \\ Harcourt, PMB 5323, Port Harcourt, Nigeria. E-mail: nath.abraham@uniport.edu.ng
}

Received: January 12, 2016

doi:10.5430/wje.v6n1p40
Accepted: January 31, $2016 \quad$ Online Published: February 20, 2016

URL: http://dx.doi.org/10.5430/wje.v6n1p40

\begin{abstract}
The study examined Governments' Involvement in Safety Management in Public Early Childhood Education Centres (ECECs) in Rivers State. Two research questions and two hypotheses guided the study which adopted the descriptive survey design. The population of the study comprised of five hundred and ten (510) ECECs in the twenty three (23) Local Government Areas in Rivers State. There were 205 supervisors and 2752 teaching staff of which 510 are head teachers. A sample of 120 ECECs was selected using the proportionate stratified random sampling technique. A total of 1000 respondents was used for the study. A questionnaire titled "Government Involvement in Safety Management in ECECs (GISMQ)"developed by the researchers, was the instrument used for the study. The questionnaire had a face and content validation and a reliability index of 0.80 was established using the Cronbach alpha statistics. The mean and standard deviation were used in answering the research questions while $\mathrm{z}$ test was used in testing the hypotheses at 0.05 alpha level. The findings of the study revealed that the government was not involved in the training and retraining of ECECs staff, maintenance of facilities, provision of adequate fund for ECECs and the use of professionally trained security personnel. These practices could bring to naught all other efforts made at instituting safety management in schools as children become exposed to unnecessary dangers and hazards. It was recommended that provisions of adequate fund for ECECs be made by the government for its effective and smooth operation; Training and retraining of ECECs staff to update their knowledge on issues concerning child care; the use of professionally trained security personnel to beef up school security and maintenance of school facilities to ensure facilities relevance in providing safe school environment.
\end{abstract}

Keywords: government's involvement; safety management; early childhood education centres (ECECs)

\section{Introduction}

One of the roles of any government is to ensure the safety of her citizens, irrespective of their size, age, religion, state of origin etc. Ensuring safety implies providing an environment where persons are free from danger or harm. Educational institutions are involved in many activities that present a range of hazards, dangers and harm. These hazards and associated risks must however be managed to ensure the provision of a safe school environment for the students and teachers.

Research has shown that school experiences can be an emotional and academic stabilizing force for children, particularly when they are in transition or crisis (Madumere-Obike, Oragwu \& Nwabueze, 2013). In other words, the school environment affects students' performance either positively or negatively and also influences students' enrolment and health behaviours. A positive school environment creates an optimal setting for teaching and learning. It enhances motivation, increases educational aspiration, improves attendance and retention amongst students and promotes quality teaching and learning (Madumere-Obike, Oragwu \& Nwabueze, 2013).

Creating a positive school environment can be achieved through the collective efforts between the stakeholders. In the case of public Early Childhood Education Centres (ECECs), the government is a major stakeholder. The onus of providing the needed safe environment in ECEC lies on the government. As education remains an indisputable requisite for meaningful development in any nation, the need for government to provide a positive school environment in ECEC cannot be overemphasized. 
Early Childhood Education (ECE) is education given to children under the age of six (6). This education is important as it helps in the formation of the intelligence, personality and social behaviour of the child. Up until 1977, Early Childhood Education was not given a serious consideration. Children were catered for by their mothers or other relatives. They were left out of school. With the coming of the missionaries during the colonial days, classes were organized for such children but without any regulations. According to Tor-Anyiin (2008), groupings for instruction in these classes were not age-based and so children aged six or even more could be found in these classes. Since there were no clearly spelt out regulations, little or no attention could have been given to the safety of the students and teachers. Each of these centres was run independently.

The need for the establishment of Early Childhood Education Centres became a necessity with the phasing out of such infant schools, modernization and a shift of women's roles from homemakers to different careers. Modern societies now show serious concern for the education of their young ones by providing the needed support to prepare them to succeed later in life. The Federal Government of Nigeria also recognized the importance of ECEC and gave it prominence in its National Policy on Education as one of the programmes in Nigerian education system.

Preprimary education as it is referred to in the policy, was to be established in existing primary schools. Nursery education, kindergarten, pre-primary education, day care, infant school, crèche etc are all names used to address Early Childhood Education around the world. For the purpose of uniformity, Early Childhood Education is adopted in this research. Early Childhood Education is an important aspect of education for national development. The world conference on Education For All (EFA) and the United Nations Convention on the Rights of the Child emphasized urgent priority to ensure access to improved quality education for all children (Nakpodia, 2011).

Adenipekun (2004) gave reasons in support for ECE:

- From conception to six years of age, children undergo rapid mental, social and physical development to the extent that by the age of six, their brains develop to almost the size of an adult;

- The convention on the rights of the child stipulates that children have a right to live and develop to their full capacity;

- Moral and social values postulate that through children, societies pass on values and culture from generation to generation;

- Supporting the development of the child physically and mentally leads to increased enrolment and improved performance of society generally;

- Provision of early child care facilities offers equal opportunities to children from both the privileged and disadvantaged homes;

- ECE programmes are used as an entry point for other developmental activities which will benefit the entire community.

Armstrong (2009) rightly pointed out that safety management requires the active involvement of all stakeholders. Although the onus of instituting safety management in public ECE falls on the government as they are the owners of these centres, there needs to be an active involvement of other stakeholders- the community, the parents, regulatory bodies, health organizations etc. in order to achieve the aims of ECEC. The Nigerian Education Research and Development Council (NERDC) (2004) developed a national minimum standard for Early Childhood Education Centres in Nigeria. This was to serve as a guideline for both the private and public operators and stakeholders. Through the establishment of these standards the private operators who had been in control of ECEC without any major regulatory policies were to be under check.

Odiagbe (2015) asserts that the Federal Government of Nigeria adopted an integrated and holistic approach for the care and support given to children less than 5 years. The objectives of relevant sectors were incorporated to ensure positive outcomes in terms of cognitive achievement, care and development. In this regard, the National Policies on Education, Food and Nutrition, Health and the Child Rights Acts states that ECE in Nigeria:

- Provide care and support to the child in the form of good nutrition and health, healthy and safe environment, psycho-social stimulation, protection and security.

- Inculcate in the child the spirit of enquiry and creativity through the exploration of nature, the environment, art, music and playing with toys under proper supervision.

- Effect a smooth transition from the home to the school.

- Prepare the child to adapt successfully with their current context changes. 
- Provide adequate care and supervision for the children while their parents are at work (on the farms, in the markets, offices, industry, etc.)

- Inculcate social norms that are culturally relevant, skills and behaviours which allow them to function effectively in their current context (NERDC, 2004:6).

Achieving the objectives of ECE requires the provision of a healthy, safe environment equipped with the necessary facilities and resources. According to UNICEF (2011), the quality and intensity of care, nutrition and stimulation children receive during their early childhood determines to a large extent the level of physical and cognitive development they can attain. As such, the smallest detail can have an impact on the achievement of the objectives of ECE.

Heckman (2000) specified that a good ECE programme should:

be built around a good learning environment with an effective, well-thought out curriculum; begin at an appropriate starting age; be provided in a physical space that is safe and one that has certain specialized facilities; be given by professional caregivers, attentive to the individualized needs and progress of the child and include the involvement of parents (p.50)

Safety in Early Childhood Centres cannot be ignored because of the need of providing children the needed support in an environment free from dangers, hazards and other risks. Safety management as defined by Bluff (2003) includes the "systematic identification of hazards, assessment and control of risks, evaluation and review of risk control measures to ensure that they are effectively implemented and maintained". Abraham and Asodike (2011) rightly observed that it costs less in terms of money and time to maintain a healthy school environment. Safety management reduces costs, increases efficiency and improves the morale of the employees (Hughes \& Ferret, 2013). It also sustains any business as threatening accidents are averted. Through the institution of safety management in ECECs, law suits from parents and the public can be avoided and also sanctions from regulatory bodies avoided.

A school is a very significant personal and social environment for pupils. Effective schools have school environments that ensure that school children are physically safe, emotionally secured and are psychologically enabled to succeed. ECE schools should therefore aim at developing an environment in which the children are motivated and able to learn. Staff members should be friendly and welcoming to children and attend to all their health and safety needs (Eresimade \& Eze, 2008).

Bluff (2003) also opined that effective safety management assigns responsibility to competent personnel. Samuel (2014) further opined that effective safety management systems require the implementation of core structures, processes and action by key players. As a key player in the establishment of public Early Childhood Education Centres, the government has the responsibility of ensuring that ECECs are sited in a safe, healthy environment; responsibilities assigned to competent personnel in the Ministry of Education - directors, supervisors etc., in schools - teachers, head-teachers, other staff etc., health sector etc., who will determine and implement the required preventive measures to ensure safety at school.

NERDC (2004) clearly stipulates government involvement in ECEC as licensing, supervision/monitoring for quality control, training of suitably qualified personnel and provision of infrastructure, personnel and gender-fair instructional materials. Quality control is expected to be instituted by supervision/monitoring. This can be achieved through the Ministry of Education, supervisors, school heads and other designated personnel. Regulatory policies are instituted and compliance ensured for quality control. An effective ECEC cannot function in a vacuum. There needs to be a conducive school environment. In order to provide the needed quality and intensity of care and stimulation children need, attention must be paid to details in the school environment. The physical, social, psychological and emotional environment of the ECEC need to be child friendly i.e. taking the needs of the child into serious consideration. As such, only suitably qualified staff need to be employed, child-friendly facilities need to be in place with the school environment welcoming to ensure the comfort and stability of the child at school.

Although the government has set up a policy framework for ECEC, Amadi (2010) revealed in his study that quality control is always compromised as government officials are "sorted" out with huge sums of money, leaving innocent children at the mercy of their teachers. He also revealed the inability of the state arm of government to provide the required checks and balances for quality control in primary schools of which the ECEC is a part.

The interest of this paper was to consider government involvement in instituting safety management in early childhood education centres. It is necessary to understand that providing quality education for young children means building the future of any nation. This cannot be achieved with unsafe conditions and unsafe practices. An 
understanding of the importance of safety will help the government formulate regulatory policies and strategies for instituting safety in ECEC.

\section{Statement of Problem}

Parents send their little children ( 0 - 5yrs old) to Early Childhood Education Centres mainly because they need a safe place for them to stay while at work. They see the ECEC as an "extension of the home" and the caregivers as capable to care for their children just as they would have done. However, certain practices have the potential of turning parents expectations of sending their children to ECEC into a nightmare. Every other day, there are reports of children being exposed to varying degrees of accidents, hazards or risks. Some get away with minor scratches, others maybe unlucky as they have either permanent scars or pay the ultimate price.

ECE is not only where children are expected to be cared for under proper supervision, but also where they can explore and learn through inquiry and creativity, exploration of nature and the environment. ECE therefore needs to be provided a positive and welcoming atmosphere, from the physical environment of the school buildings and infrastructures to the emotional wellbeing of the child. After the recognition of ECE by the Federal Government, ECE was still left in the hands of private operators without any major regulatory policy until 2004. With the exhibition of such disturbing attitude by the government, the researcher would want to find out if the Nigerian government is actually involved in ensuring safety in ECECs. Apart from regulatory policies, what other actions are taken by the government to ensure the safety of school children?

\section{Aim and Objectives of the Study}

The aim of this study was to examine government's involvement in safety management in public ECECs in Rivers State. Specifically, the objectives were to:

1. find out the rationales for providing early childhood education programmes in Rivers State.

2. examine government's involvement in safety management in public ECECs in Rivers State.

\section{Research Questions}

1. What are the rationales for providing early childhood education programmes in Rivers State?

2. How is government involved in safety management in public ECEC in Rivers State?

\section{Hypotheses}

1. There is no significant difference between the scores of supervisors and head-teachers on the rationales for providing early childhood education programmes in Rivers State.

2. There is no significant difference between the scores of teachers and head-teachers on government involvement in safety management in public ECECs in Rivers State.

\section{Theoretical Framework}

This study is guided by two theories:

- Domino theory of accident causation; and

- Safety culture theory

\subsection{Domino Theory of Accident Causation}

This theory was propounded by Heinrich in 1931 who likened accident causation to a line of dominoes falling over. Heinrich used five metaphoric dominoes - social environment and ancestry, faults of persons; unsafe acts/unsafe conditions; accident and injuries to explain accident causation. In his explanation, injuries were caused by accidents which are due to unsafe acts and condition consciously or unconsciously caused by the faults of persons, shaped by their social environment and ancestry (hereditary). Preventing these dominoes from falling over simply requires the removal of the unsafe acts or conditions.

Heinrich (1959) in Hollangel (2007) also opined that “... no safety procedure is complete or satisfactory that does not provide for the... correction or elimination of physical hazards". In context, the government can be said to be involved in complete or satisfactory safety management in ECECs when efforts are geared towards the correction or 
elimination of physical hazards. School children are however exposed to other hazards. According to the World Health Organization (2006), children are exposed to physical abuse, sexual abuse, emotional and psychological torture which usually result in actual or potential harm in their health and development.

One expectation of parents who send their children to ECEC is that they be nurtured in a safe and healthy environment. In as much as the physical environment is important, the psychological, emotional and social environments of an ECEC are important aspects that must also be properly organized to correct or eliminate actual or potential harm to school children. The government been involved in safety management in ECEC therefore requires an organization of these different but interdependent environments in order to eliminate hazards.

\subsection{Safety Culture Theory}

The safety culture theory originated from the works of Schien (1992) on organizational culture. Organizational culture is the behavior of workers in an organization. This behavior is shaped by the deeply rooted organizational beliefs held in high esteem so as to achieve organizational goals. Applying this to safety, several contributors. Rasmussen (1997); Reason (1992); Turner (1998); Leveson (2004), came up with the safety culture theory. When safety beliefs, which are deeply rooted in organizational goals are shared in organizations, workers' safety behaviours are unconsciously shaped with the result being business success.

Shared safety beliefs are fundamental to developing a safety culture in ECECs. It is in generating and embedding these beliefs that the leadership is most valuable. This is so as leadership help others to arrive at a better understanding of themselves, of the issues at hand and to use this greater understanding to accomplish group goals (Okorie, 2012). When the government is involved in instituting a safety culture in ECEC, the staff are directed on good safety beliefs and their safety behaviours are shaped. This helps in eliminating unsafe acts and conditions which according to Heinrich is one major cause of accidents and injuries in organizations.

\section{Methodology}

This study adopted a descriptive survey design with a population of 510 public Early Childhood Education Centres in Rivers State, with 2752 teachers of which 510 are head teachers and 205 supervisors. A sample size of 120 ECEC representing $24 \%$ of the population was drawn using the proportionate stratified random sampling and balloting without replacement technique. A total of 1000 respondents (120 supervisors and 880 teaching staff) was used for the study. The instrument used for data collection was a questionnaire titled "Government Involvement in Safety Management in ECEC Questionnaire (GISMQ), developed by the researchers. The instrument had a face and content validation and a reliability index of 0.80 was established using the Cronbach Alpha Statistics. 1000 copies of the questionnaire were administered with the help of 4 research assistants. 940 viable copies were retrieved and used for data analysis. The mean and standard deviation were used to answer the research questions while z-test was used to test the hypotheses at 0.05 level of significance.

\subsection{Data Analysis}

Research Question 1: What are the rationales for providing Early Childhood Education programme in Rivers State?

Analysis on Table 1 shows the respondents' (supervisors and head-teachers) scores on rationales for providing ECE programmes. The result shows that respondents have a high agreement on the areas examined, which are providing children the right to develop to full capacity; continuous capacity building; supporting the development of the child; providing equal opportunities for the privileged and underprivileged children; an entry point to other developmental activities; improved performance of the nation and integration of different stakeholders in child development. 
Table 1. Mean ( $\overline{\boldsymbol{x}}$ ) and Standard Deviation (SD) of Respondents' Scores on the Rationales for Providing Early Childhood Education Programmes in Rivers State

\begin{tabular}{|c|c|c|c|c|c|c|c|}
\hline \multirow[t]{2}{*}{$\mathbf{S} / \mathbf{N}$} & \multirow[t]{2}{*}{$\begin{array}{l}\text { Rationales for providing } \\
\text { programmes in Rivers State }\end{array}$} & \multicolumn{2}{|c|}{$\begin{array}{l}\text { Supervisors } \\
\mathrm{N}=120\end{array}$} & \multicolumn{2}{|c|}{$\begin{array}{l}\text { Head teachers } \\
N=120\end{array}$} & \multirow[t]{2}{*}{ Mean set } & \multirow[t]{2}{*}{ Remark } \\
\hline & & $\bar{x}$ & SD & $\bar{x}$ & SD & & \\
\hline 1. & $\begin{array}{l}\text { Provide children the right to develop to } \\
\text { full capacity }\end{array}$ & 3.27 & 1.21 & 3.31 & 1.29 & 3.29 & $\begin{array}{l}\text { High } \\
\text { agreement }\end{array}$ \\
\hline 2. & Continuous capacity building & 3.01 & 1.02 & 3.33 & 1.31 & 3.16 & $\begin{array}{l}\text { High } \\
\text { agreement }\end{array}$ \\
\hline 3. & Support the development of the child & 2.99 & 1.01 & 2.95 & 0.98 & 2.97 & $\begin{array}{l}\text { High } \\
\text { agreement }\end{array}$ \\
\hline 4. & $\begin{array}{l}\text { Provide equal opportunities for the } \\
\text { privileged and underprivileged children }\end{array}$ & 2.88 & 0.96 & 2.92 & 0.97 & 2.90 & $\begin{array}{l}\text { High } \\
\text { agreement }\end{array}$ \\
\hline 6. & $\begin{array}{l}\text { As an entry point to other developmental } \\
\text { activities } \\
\text { Improved performance of the nation }\end{array}$ & 3.07 & 1.05 & 3.09 & 1.07 & 3.08 & $\begin{array}{l}\text { High } \\
\text { agreement } \\
\text { High }\end{array}$ \\
\hline 7 & Integration of different stakeholders in & 3.09 & 1.07 & 3.11 & 1.09 & 3.10 & agreement \\
\hline 1. & $\begin{array}{l}\text { Integration of different stakenolders in } \\
\text { child development }\end{array}$ & 3.19 & 1.15 & 3.21 & 1.17 & 3.20 & $\begin{array}{c}\text { agreement } \\
\text { High } \\
\text { agreement }\end{array}$ \\
\hline
\end{tabular}

\section{Scale}

$0.00-1.49$ : Very low agreement

$1.50-2.49$ : Low agreement

$2.50-3.49$ : High agreement

$3.50-4.00$ : Very high agreement

Research Question 2: How is the government involved in safety management in ECECs in Rivers State?

Analysis on Table 2 shows the respondents' scores on government involvement in safety management in ECECs in Rivers State. The results show that respondents highly agree that government is involved in instituting safety in ECECs by instituting regulatory policies; monitoring school activities through designated authorities; daily supervision of school activities through school heads; closure of school on persistent failure to meet stipulated standards; equipping ECEC with necessary facilities and infrastructure, employing suitably qualified teaching staff; providing good ECEC sanitation ground; Ensuring staff compliance to safety regulations; promoting effective classroom management skills; preventing child abuse; preventing child neglect; providing a child friendly environment; providing well structured school buildings and assigning responsibilities to competent personnel. However, the respondents' scores show a low agreement on provision of funds by government; training and retraining of ECEC staff; maintenance of school facilities and use of professionally trained security personnel. 
Table 2. Mean ( $\overline{\boldsymbol{x}}$ ) and Standard Deviation (SD) of Respondents' Scores on Government Involvement in Safety Management in Early Childhood Education Programmes in Rivers State

\begin{tabular}{|c|c|c|c|c|c|c|c|}
\hline \multirow[t]{2}{*}{$\mathbf{S} / \mathbf{N}$} & \multirow[t]{2}{*}{$\begin{array}{l}\text { Government involvement in instituting } \\
\text { safety in ECECs in Rivers State }\end{array}$} & \multicolumn{2}{|c|}{$\begin{array}{l}\text { Teachers } \\
\mathbf{N}=700\end{array}$} & \multicolumn{2}{|c|}{$\begin{array}{l}\text { Head } \\
\text { teachers } N= \\
120\end{array}$} & \multirow[t]{2}{*}{$\begin{array}{l}\text { Mean } \\
\text { set }\end{array}$} & \multirow[t]{2}{*}{ Remark } \\
\hline & & $\bar{x}$ & SD & $\bar{x}$ & SD & & \\
\hline 8. & Instituting regulatory policies & 3.14 & 1.08 & 3.26 & 1.23 & 3.20 & High agreement \\
\hline 9. & $\begin{array}{l}\text { Monitoring school activities through } \\
\text { designated authorities }\end{array}$ & 3.38 & 1.27 & 3.55 & 1.38 & 3.47 & High agreement \\
\hline 10. & $\begin{array}{l}\text { Daily supervision of school activities } \\
\text { through school head }\end{array}$ & 3.30 & 1.25 & 3.26 & 1.23 & 3.28 & High agreement \\
\hline 11. & $\begin{array}{l}\text { Closure of school on persistent failure to } \\
\text { meet stipulated standards }\end{array}$ & 3.27 & 1.23 & 2.93 & 1.00 & 3.10 & High agreement \\
\hline 12. & Maintenance of school facilities & 1.27 & 0.21 & 1.71 & 0.31 & 1.52 & Low agreement \\
\hline 13. & $\begin{array}{l}\text { Equipping ECEC with necessary facilities } \\
\text { and infrastructures }\end{array}$ & 3.09 & 1.06 & 3.17 & 1.10 & 3.13 & High agreement \\
\hline 14. & Employing suitably qualified teaching staff & 3.40 & 1.29 & 3.20 & 1.15 & 3.30 & High agreement \\
\hline 15. & Training and retraining of ECEC staff & 2.12 & 0.44 & 2.49 & 0.54 & 2.31 & Low agreement \\
\hline 16. & Providing good sanitation ECEC ground & 3.26 & 1.23 & 2.94 & 1.00 & 3.10 & High agreement \\
\hline 17. & $\begin{array}{l}\text { Ensuring staff compliance to safety } \\
\text { regulations }\end{array}$ & 3.38 & 1.27 & 3.55 & 1.38 & 3.47 & High agreement \\
\hline 18. & $\begin{array}{l}\text { Promoting effective classroom management } \\
\text { skills }\end{array}$ & 3.45 & 1.31 & 3.55 & 1.38 & 3.50 & High agreement \\
\hline 19. & Preventing child abuse & 3.46 & 1.32 & 3.32 & 1.26 & 3.39 & High agreement \\
\hline 20. & Preventing child neglect & 3.07 & 1.04 & 3.11 & 1.08 & 3.09 & High agreement \\
\hline 21. & Providing child friendly environment & 2.86 & 0.91 & 3.49 & 1.35 & 3.18 & High agreement \\
\hline 22. & Provision of fund by government & 2.06 & 0.41 & 2.28 & 0.50 & 2.17 & Low agreement \\
\hline 23. & $\begin{array}{l}\text { Use of professionally trained security } \\
\text { personnel }\end{array}$ & 2.11 & 0.43 & 1.57 & 0.29 & 1.84 & Low agreement \\
\hline 24. & Involving other stakeholders & 3.21 & 1.18 & 3.13 & 1.07 & 3.17 & High agreement \\
\hline 25. & Well structured school buildings & 3.19 & 1.16 & 3.29 & 1.29 & 3.24 & High agreement \\
\hline 26. & $\begin{array}{l}\text { Assigning responsibility to competent } \\
\text { personnel }\end{array}$ & 2.99 & 1.01 & 3.07 & 1.04 & 3.03 & $\begin{array}{l}\text { High agreement } \\
\text { High }\end{array}$ \\
\hline & Aggregate & 2.92 & 0.99 & 2.97 & 1.01 & 2.95 & agreement \\
\hline
\end{tabular}

Scale

$0.00-1.49$ : Very low agreement

$1.50-2.49$ : Low agreement

2.50 - 3.49: High agreement

$3.50-4.00$ : Very high agreement

\subsection{Test of Hypotheses}

Hypotheses 1: There is no significant difference between the mean scores of supervisors and head-teachers on the rationales for providing early childhood education programmes in Rivers State.

Table 3. z-test analysis of difference between the Mean ( $\overline{\boldsymbol{x}})$ and Standard Deviation (SD) of respondents' score on the rationales for providing early childhood education programmes in Rivers State

\begin{tabular}{llclcccc}
\hline Respondents & N & $\overline{\boldsymbol{x}}$ & SD & df & z. cal & Critical value & Decision \\
\hline Supervisors & 120 & 3.07 & 1.08 & \multirow{2}{*}{238} & \multirow{2}{*}{0.42} & \multirow{2}{*}{ \pm 1.96} & Hypothesis \\
Head teachers & 120 & 3.13 & 1.13 & & & & accepted \\
\hline
\end{tabular}

Key: N - Number of respondents; SD - Standard Deviation; df - Degree of Freedom; z-cal - z calculated 
Table 3 shows a z-cal of 0.42 at 238 degree of freedom and 0.05 level of significance. Since the z. cal of 0.42 is less than the z. critical value of 1.96 , hypotheses one is therefore accepted. This means that there is no significant difference between the mean and SD of respondents' scores on the rationales for providing early childhood education programmes in Rivers State.

Hypothesis 2: There is no significant difference between the scores of teachers and head-teachers on the involvement of government in safety management in ECECs in Rivers State.

Table 4. z-test Analysis of Difference between the Mean ( $\overline{\boldsymbol{x}}$ ) and Standard Deviation (SD) of Respondents' Score on the Involvement of Government In Safety Management in Early Childhood Education Programmes in Rivers State

\begin{tabular}{llcccccc}
\hline Respondents & $\mathbf{N}$ & $\overline{\boldsymbol{x}}$ & SD & df & z. cal & $\begin{array}{c}\text { Critical } \\
\text { value }\end{array}$ & Decision \\
\hline Teachers & 700 & 2.92 & 0.99 & 818 & 0.51 & \pm 1.96 & $\begin{array}{c}\text { Hypothesis } \\
\text { accepted }\end{array}$ \\
Head teachers & 120 & 2.97 & 1.01 & &
\end{tabular}

Key: N - Number of respondents; SD - Standard Deviation; df - Degree of Freedom; z. cal - z calculated

Table 4 shows a z-calculated value of 0.51 at 818 degree of freedom and 0.05 level of significance. Since the $\mathrm{z}$. calculated value of 0.51 is less than $z$. critical value of 1.96 , hypothesis two is therefore accepted. This means there is no significant difference in the scores of teachers and head-teachers on the involvement of government in instituting safety in ECECs in Rivers State.

\section{Discussion of Findings}

Supervisors and head-teachers in ECECs under study were in high agreement on the rationales for providing early childhood education programmes in Rivers State. These findings agree with Adenipekun's (2004) opinion on the rationales for establishing early childhood education programmes. Heckman (2000) stated that early childhood education is an asset of immense value in the academic pursuit of a child. Early childhood experiences exposes and prepares the child for the future. Madumere-Obike, Oragwu and Nwabueze (2013) also opine that it is an effective and efficient programme that aids in unlocking and developing a child's latent abilities, attitudes and other forms of positive values in the society. These findings also show that the Rivers State Government complies with national (NERDC) and international regulatory bodies (UNICEF) on the need to provide quality care for children to develop fully.

The findings revealed that rationales for providing early childhood education programmes in Rivers State include: Providing children the right to develop to full capacity; continuous capacity building; support for the development of the child; providing equal opportunities for the privileged and underprivileged children; an entry point to other developmental activities; improved performance of the nation and integration of different stakeholders.

The results of this study from responses of teachers and head-teachers showed the level of government involvement in safety management in Early Childhood Centres in Rivers State. Respondents are in high agreement in government involvement through: Instituting regulatory policies; monitoring school activities through designated authorities; daily supervision of school activities through school heads; closure of schools on persistent failure to meet stipulated standards; equipping ECECs with necessary facilities and infrastructures; employing suitably qualified teaching staff; providing good sanitation ECECs ground; Ensuring staff compliance to safety regulations; promoting effective classroom management skills; preventing child abuse; preventing child neglect; providing child friendly school environment; involving other stakeholders; well-structured school buildings and assigning responsibilities to competent personnel. However, respondents were in low agreement on government's involvement in training and retraining of ECECs staff; maintenance of school facilities; provision of fund and use of professionally trained security personnel.

Studies by Peretemode (1991, 2006), Majasan (1995) and Ofojebe (2010) have shown that inadequate provision of funds affects teachers' motivation which in turn affects their performance in contributing towards achieving educational goals. Peretemode (2006) defined motivation as the process of stimulating a person to act in ways that will accomplish desired goals. Ofojebe (2006) opined that teacher motivation is a way of empowering teachers by providing a conducive working climate so they become satisfied, dedicated and effective in performing their task.

Government's low funding of the ECECs could lead to the relegation of safety to the background. Having 
unmotivated teachers because of lack of basic infrastructures, facilities and poor working conditions, which they are subjected to as a result of limited funds, cannot be ruled out. Government's active involvement in safety management however ensures a motivated ECEC workforce. This can be achieved through the provision of adequate fund to provide teachers the needed environment for effectiveness.

NERDC (2004) recommends that government be involved in training of suitably qualified personnel in ECECs. Training moulds the thinking of employees and leads to quality performance as the chances and incidences of errors, accidents, hazards and other risks as a result of personnel's lack of knowledge are reduced to the barest minimum.

Kpee (2013) defined maintenance of school facilities as "an integral part of efforts needed to check, improve, repair, renew, remodel and modify school facilities to ensure the effective use of such facilities for continuous relevance. In other words, effective schools ensure that at the minimum school physical facilities do not expose children to unnecessary dangers and mishaps. Low allocations to education over the years have affected ECECs' facilities status. The low agreement of respondents on maintenance of school facilities and a high agreement on provision of school facilities and infrastructure show that school facilities are actually provided by the government but are left to rot away because of lack of maintenance.

The government not maintaining ECECs facilities and infrastructures renders them irrelevant for continuous use as they could be the cause of minor or fatal accidents to school children. Such facilities end up creating unsafe conditions at the centres, which according to Heinrich causes accidents. School children need not be exposed to such hazards. Non-maintenance of school facilities eventually brings to naught all government's efforts at instituting safety in schools.

One way of ensuring school security is by having effective security measures in place. The 'Safe School Initiatives' launched at the World Economic Forum in Nigeria (2014) recommended the use of armed school guards and the training of school security personnel in collaboration with the law enforcement agencies. The essence is to have trained security personnel manning school gates and premises. The duty of security personnel demands vigilance, alertness, possession of certain skills and capabilities for discerning crimes and disorder in and around the school. Due to the increase in terrorism and crimes around the country, there is the need for the use of professionally trained security men who have undergone special trainings with the military (if need be), in the ECECs in Rivers State. The use of non-professional security men who themselves are not safety cautious in ECECs only expose these children to unnecessary risks. When such security blunders are checked by using professional security grounds, the government will be one step in the right direction in ensuring safer ECECs.

\section{Conclusion and Recommendations}

The level of government's involvement in safety management in public Early Childhood Education Centres in Rivers State is low. This certainly calls for concern considering the security problems prevalent in the state at the moment. These crises are in the forms of kidnapping, arson to the more pronounced problem of Boko Haram insurgency in the North East. It is on this basis that it is recommended that professionally trained security personnel working with the military, if need be, be used to beef up school security.

Achieving the rationale for providing ECEC programmes in Rivers State demand that the environment be designed and activities organized with the interest of the child placed as top priority. Instituting a safety culture in ECECs goes a long way in ensuring that school children are nurtured in a safe, healthy and comfortable school environment. This can be achieved by the government adequately providing funds for the effective operations of the school and training and retraining of ECECs staff in order to update their knowledge on issues concerning child care.

Construction of beautiful ECECs without being involved in the maintenance of the facilities will be a complete waste of investments in the long run. This is so because facilities will rot away and become irrelevant in the provision of the needed conducive, comfortable, healthy and safe school environment. The staff becoming demoralized as a result of working under harsh conditions cannot be ruled out. Considering the fact that the staffs are instrumental in achieving the ECEC's goals, the government should be actively involved in their training and retraining and also maintenance of ECEC facilities. This will place teachers on the right platform as the needed resources are provided.

\section{References}

Abraham, N. M., \& Asodike, J. D. (2011). Environmental safety in early childhood education centres in Port Harcourt municipality. African Journal of Community \& Development, 3(1).

Adenipeku, O. (2004). Government falters in early childhood education. Vanguard Newspapers. Apapa, 20: 56565. 
Amadi, U. P. W. (2010). Foundations of entrepreneurship development. Unpublished note mimeograph, Federal College of Education (Technical), Umunze.

Armstrong, M. (2009). Handbook of human resource management practice. India: Replika Press Pvt Ltd.

Bluff, L. (2003). Systematic management of occupational health and safety. Being a working paper for the National Research Centre ACT: Australian National University. Retrieved from http://dspace.anu.edu.au/bitstream/1885/39967/OHSMS.wp20.pdf

Eresimadu, F. N. J., \& Eze, D. (2008). Management of nursery staff personnel in Anambra State: Problems and prospects. In B. O. Igboabuchi \& D. O. Eze (eds.), Preprimary education in Nigeria. (p.118-129) Owerri: Alphabet Nigerian Publishers.

Heckman, J. J. (2000). The case for investing in disadvantaged young children. Dublin: Yale University Press.

Hollangel, E. (2009). Safer complex industrial environments: A Human factors approach. CRC press. http://dx.doi.org/10.1201/9781420092493

Hughes, P., \& Ferret T. (2013). International health and safety at work ( $2^{\text {nd }}$ edition.). India: Replika Press Pvt Ltd.

Kpee, G. G. (2013). The school plant planning. In J. D. Asodike, J. M. Ebong, S. O. Oluwuo \& N. M. Abraham (Eds.), Contemporary administration and teaching issues in Nigeria schools. Owerri: Alphabet Nigerian Publishers.

Madumere-Obike, C. U., Oragwu, A., \& Nwabueze, A. I. (2013). Environmental management for effective teaching and learning in secondary schools in Rivers State. Paper presented at the Conference of Nigerian Academy of Education, in Abuja.

Majasan, J.A. (1995). The Teachers' Profession: A Manual for Professional Excellence. Ibadan: Spectrum Books Ltd.

Nakpodia, E. (2011). Work environment and productivity among primary school teachers in Nigeria. International Multidisciplinary Journal Ethiopia, 5(5), 22:367-381.

Nigerian Educational Research and Development Council (NERDC) (2004). National minimum standards for early childcare centers in Nigeria. Abuja: Federal Ministry of Education.

Odiagbe, S. I. (2015). The national minimum standard on early child care centres (ECEC) in Nigeria and the status of pre-primary education in Uhunmwode Local Government Area of Edo State. American Journal of Educational Research, 3(4), 399-405.

Ofojebe, W.N. (2010). Teachers' motivation and its influence on quality assurance in the Nigerian educational system. African Research Review, 4(2), 398-417. http://dx.doi.org/10.4314/afrrev.v4i2.58352

Okorie, N.C. (2012). Organizational setting of leadership: Theoretical perspectives. Oweri: Totan publications.

Peretemode, V.F. (2006). Educational administration: Applied concepts and theoretical perspective. Lagos: Joja Press Limited.

Samuel, O. O. (2014). A study of safety management in the Nigerian construction industry. Journal of Business and Management, (10SR-JBM), 1-10.

Tor-Anyiin, S. A. (2008). Origin, growth and development of pre-primary and primary education in Nigeria. Makurdi: Selfer Academic Press.

World Economic Forum Africa (2004). Safe school Initiatives. Retrieved 12/12/2015 From http://www.ssinigeria.org.ng/

World Health Organization and International society for prevention of child abuse and neglect (2006). The nature and consequences of child maltreatment. Preventing child maltreatment: a guide to taking action and generating evidence (PDF) 1 February, 2016 Geneva, Switzerland. Retrieved 6-02-1-2016 from whqlibdoc.who.int $>9241594365$ _eng 